\title{
Plasma biomarkers of mouse aging
}

\author{
Juan Ding • John J. Kopchick
}

Received: 8 April 2010 /Accepted: 25 August 2010/Published online: 15 September 2010

(C) American Aging Association 2010

\begin{abstract}
Normal aging is accompanied by a series of physiological changes such as gray hair, cataracts, reduced immunity, and increased susceptibility to disease. To identify novel biomarkers of normal aging, we analyzed plasma proteins of male mice longitudinally from 2 to 19 months of age. Plasma proteins were analyzed by two-dimensional gel electrophoresis and identified using mass spectrometry (MS), MS/MS and liquid chromatography MS/MS. We found that many plasma proteins exist as multiple isoforms with different masses and/or charges. Thirty-nine protein spots (corresponding to six distinct proteins) have been identified, 13 of which exhibited significant changes with age. For example, several proteins increased significantly during aging including one isoform of transthyretin, two isoforms of haptoglobin, and three isoforms of
\end{abstract}

Electronic supplementary material The online version of this article (doi:10.1007/s11357-010-9179-z) contains

supplementary material, which is available to authorized users.

J. Ding · J. J. Kopchick $(\bowtie)$

Edison Biotechnology Institute, Ohio University,

1 Water Tower Drive, The Ridges,

Athens, OH 45701, USA

e-mail: kopchick@ohio.edu

J. J. Kopchick

Department of Biomedical Sciences,

College of Osteopathic Medicine, Ohio University,

Athens, OH 45701, USA immunoglobulin kappa chain. Conversely, several proteins decreased significantly during aging including peroxiredoxin-2, serum amyloid protein A-1, and five isoforms of albumin. Identification of these proteins provides new biomarkers of normal aging in mice. If validated in humans, these biomarkers may facilitate therapeutic interventions to identify premature aging, delay aging, and/or improve healthspan of the elderly.

Keywords Mouse aging · Biomarkers · Proteomics · Two-dimensional gel electrophoresis $\cdot$ Plasma

\section{Introduction}

Whether there are viable therapeutic targets that would delay or slow the aging process is currently being discussed. To date, the only intervention consistently shown to affect aging is caloric restriction (CR) which has been shown to increase lifespan in a diverse range of species from yeast to monkeys (Mair and Dillin 2008). In Rhesus monkeys, CR reduces the incidence of age-related deaths and delays the onset of age-associated diseases including cancer, diabetes, cardiovascular diseases, and brain atrophy (Colman et al. 2009). In humans, although no definitive study has shown an increase in lifespan, CR does improve cardiovascular functions, and reduces inflammation and age-related diseases 
such as atherosclerosis and diabetes (Holloszy and Fontana 2007).

One of the ultimate goals of the aging field is to develop therapeutic agents that may extend human lifespan, and, perhaps more importantly, improve the quality of life or 'healthspan' (Nass et al. 2009). To accomplish this, targets, or biomarkers of aging, must be identified which can be predictive of the aging process. Biomarkers of aging are biological characteristics (e.g., physiological and molecular) that change as a function of age and, therefore, are indicative of a given age period. Traditional physiological markers for old age include gray hair, cataracts (Klein et al. 2002; Harper et al. 2003), reduced skin resistance to stress (James et al. 2007), and reduced immunity (Miller 1996). Other physiological variables that are used to evaluate aging include changes in blood pressure, forced expiratory capacity, hematocrit, serum albumin, and blood urea nitrogen (Nakamura and Miyao 2007). In this regard, it has been found that systolic blood pressure and blood urea nitrogen increase with chronological age, whereas forced expiratory volume, hematocrit, and albumin decrease (Nakamura and Miyao 2007). Another aging biomarker is dehydroepiandrosterone sulfate, an adrenal steroid sulphate, which declines during normal aging in humans (Orentreich et al. 1992). Lastly, humans and other animals including mice show declined physical activity as they age, partly due to reduced neurotransmission in the central dopamine system (Ingram 2000). Although these physiological markers are available to evaluate the aging process, they are largely descriptive. Additional biomarkers, ideally specific proteins, could provide potential therapeutic targets and additional insight into the mechanisms of aging.

Serum/plasma proteins are relatively easy to access and are widely used for disease diagnosis. Serum proteins that change as a function of age (i.e., biomarkers of aging) may facilitate the elucidation of the physiological processes of aging and provide insight in therapeutic targets and intervention strategies to impede aging.

Proteomic techniques including two-dimensional gel electrophoresis (2-DE) have been used to study aging (Ballesteros et al. 2001; Gromov et al. 2003; Sato et al. 2006; Miura et al. 2007) and have led to the identification of many candidate proteins that are altered by aging. For example, older human skin expresses reduced levels of certain proteins, including manganese-superoxide dismutase, tryptophanyl-tRNA synthetase, the p85ß subunit of phosphatidylinositol 3-kinase, and proteasomal proteins PA28- $\alpha$ (Gromov et al. 2003). In rats, peroxiredoxin-2, an antioxidant enzyme, is able to be induced by irradiation in cultured astrocytes from young but less so from old rats (Miura et al. 2007). Phosphorylation of $\alpha$-tubulin is increased with age in rat astrocytes (Miura et al. 2007) and N-glycosylated proteins including cathep$\sin \mathrm{D}$, a lysosomal protease, are found to accumulate in aged rat cerebral cortex (Sato et al. 2006). Additionally, oxidized proteins have been found to be increased in senescent bacteria cells (Ballesteros et al. 2001). Since proteomics reveals the total detectable proteins in a given sample, this approach makes it possible to identify additional proteins involved in the aging process. In the present study, 2-DE followed by mass spectrometry (MS), MS/MS and liquid chromatography (LC) MS/MS was used to identify plasma biomarkers of mouse aging.

\section{Materials and methods}

\section{Animals}

Male C57BL/6J mice $(n=8)$ were evaluated in a longitudinal study through $2,4,8,12,16$, and 19 months of age. These ages represent post-puberty ( 2 months), young adult (4 months), adult (8 months), middle-age (12 and 16 months), and old age (19 months; Miller and Nadon 2000). The C57BL/ $6 \mathrm{~J}$ mouse strain used in this study has a median lifespan of $\sim 2.0-2.5$ years (Yuan 2008). As this cohort of mice approached 24 months of age, two died and one was severely ill. Therefore, proteomic analysis, blood glucose, and plasma insulin measurements were carried out up to 19 months. Another cohort (crosssectional design) of $\mathrm{C} 57 \mathrm{BL} / 6 \mathrm{~J}$ male mice, aged 6 months $(n=12), 9$ months $(n=8), 12$ months $(n=$ $8), 19$ months $(n=8)$, and 24 months $(n=9)$ were used for body composition measurements, because when the longitudinal study was initiated, the nuclear magnetic resonance (NMR) body analyzer was not available. Mice were housed two to three per cage at room temperature $\left(22^{\circ} \mathrm{C}\right)$ in a 14 -h light, 10 -h dark cycle. All mice were fed ad libitum with a standard chow diet (ProLab RMH 3000 PMI Nutrition Inter- 
national, Brentwood, MO, USA; calories proportion is $14 \%$ from fat, $26 \%$ from protein, and $60 \%$ from carbohydrates). Animal protocols were approved by Ohio University's Institutional Animal Care and Use Committee.

Body composition measurement

Body composition was measured using the Bruker Minispec NMR analyzer (The Woodlands, TX, USA) as described previously (List et al. 2009; Palmer et al. 2009). The absolute mass (grams) of lean mass, fat mass, and fluid mass of each animal was measured twice with the mean value reported.

Plasma collection

Bleeding took place at $\sim 3$ PM in ad libitum state. Blood was collected into heparinized capillary tubes following tail tip clipping after exposure to a heat lamp. Whole blood was centrifuged at $7,000 \times g$ for $10 \mathrm{~min}$ at $4^{\circ} \mathrm{C}$ and the resulting plasma was stored at $-80^{\circ} \mathrm{C}$.

Fasting glucose and insulin measurements

Because one bleeding did not contain enough plasma for both proteomics and hormone measurements, mice were bled separately for fasting glucose and insulin levels. Mice were fasted for $4 \mathrm{~h}$ and bled at $3 \mathrm{PM}$. Blood glucose was measured using a One Touch glucometer from Lifescan (Milpitas, CA, USA). Plasma insulin levels were determined using an ultrasensitive rat/mouse insulin ELISA kit following manufacturer's instructions (ALPCO, Windham, NH, USA).

2-DE

2-DE was carried out within a week after plasma collection. Total plasma protein concentration was quantified using the Bradford method (Bradford 1976) employing a protein assay reagent (Bio-Rad, Hercules, CA, USA) such that equal amounts of protein were loaded onto the gels. The method for 2-DE was previously described (Qiu et al. 2005; List et al. 2007b; Sackmann-Sala et al. 2009; Okada et al. 2010). Briefly, for each sample, 750 ug of plasma proteins were treated for $2 \mathrm{~h}$ at room temperature with a sample buffer containing $8 \mathrm{M}$ urea, $1.8 \mathrm{M}$ thiourea,
4\% zwitterionic detergent (CHAPS), and $5 \mathrm{mM}$ reducing agent tributylphosphine, and $1.5 \%(v / v)$ of protease inhibitor cocktail containing $2 \mathrm{mM}$ AEBSF, $1 \mathrm{uM}$ Phosphoramidon, $0.2 \mathrm{uM}$ aprotinin, $1 \mathrm{uM}$ leupeptin, $130 \mathrm{uM}$ bestatin, $10 \mathrm{uM}$ pepstatin $\mathrm{A}$, and 14 uM E-64 (Sigma-Aldrich, Inc., St. Louis, MO, USA). Then $15 \mathrm{mM}$ iodoacetamide was added for $30 \mathrm{~min}$ for alkylation of reduced sulfur side chains. The sample was loaded onto a $17 \mathrm{~cm}$ immobile $\mathrm{pH}$ gradient gel strip with a linear pI range of 3-10 (Bio-Rad, Hercules, CA, USA). After actively rehydrated $(50 \mathrm{~V})$ for $12 \mathrm{~h}$ at $20^{\circ} \mathrm{C}$ using a Protean isoelectric focusing (IEF) cell (Bio-Rad), the strips were subjected to first dimensional IEF at $4,000 \mathrm{~V}$ for 60,000 V-Hr. When IEF was completed, strips were incubated in a buffer containing $2 \%(w / v)$ sodium dodecyl sulfate (SDS), $0.5 \mathrm{M}$ Tris/ $\mathrm{HCl}$ ( $\mathrm{pH}$ 6.8), $20 \%(v / v)$ glycerol for $25 \mathrm{~min}$. The middle section of the strip (pI 5-8) possessing the majority of plasma proteins (List et al. 2007a) was removed and subjected to second dimension SDS polyacrylamide gel electrophoresis (PAGE). Polyacrylamide (15\%) gels $(8 \times 7 \mathrm{~cm})$ were used for the second dimension electrophoresis at a current of $25 \mathrm{~mA} / \mathrm{gel}$ until a total of $250 \mathrm{~V}-\mathrm{Hr}$ was reached. After electrophoresis, the gels were fixed overnight in a solution containing $40 \%$ ethanol and $2 \%$ acetic acid followed by washing three times in $2 \%$ acetic acid. The gels were then stained with SYPRO Orange (1:5,000) (Molecular Probes, Eugene, OR, USA) for $2 \mathrm{~h}$ using a modified protocol from (Malone et al. 2001).

\section{Quantification of proteins}

Gel images were captured using a laser-scanner Pharos FX plus (Bio-Rad) with an excitation wavelength of $488 \mathrm{~nm}$ and an emission wavelength of $604 \mathrm{~nm}$ as previously described (Sackmann-Sala et al. 2009; Okada et al. 2010). Proteins were matched across all images using PDQuest (Bio-Rad) software and manually checked and corrected when necessary. For quantification, the intensity of each protein spot was determined according to the fluorescent signal strength, and then normalized by the total density of each image using PDQuest software. The data were exported, log-transformed, and then subjected to statistical analysis. In addition, spot intensities were also presented topographically using the $3 \mathrm{D}$ viewer tool as a part of the PDQuest program. 
Protein identification by MS, MS/MS, and $\mathrm{LC} / \mathrm{MS} / \mathrm{MS}$

Proteins of interest were excised manually from the gels, lyophilized and shipped to Protea Biosciences, Inc. (Morgantown, WV, USA) for MS and MS/MS analyses using matrix assisted-laser desorption ionization (MALDI)-time of flight (TOF) and MALDI-TOFTOF. Proteins that could not be identified with MS/MS were subjected to LC/MS/MS for identification. $M S, M S / M S$, and LC/MS/MS identification of proteins
(Performed at Protea Biosciences, Inc.)

After in-gel digestion by trypsin, proteins were analyzed by ABI 4800 MALDI TOF-TOF analyzer as described previously (Qiu et al. 2005; List et al. 2007a, b; Sackmann-Sala et al. 2009; Okada et al. 2010). The MALDI MS parameters used for analyses were: MS acquisition in reflector mode, positive ion mode, mass range $=$ mass $/$ charge $(\mathrm{m} / \mathrm{z})=850-4,000$, 400 laser shots per spectrum; minimum signal/noise $(\mathrm{S} / N)=10$ for MS acquisition, 15 strongest precursors chosen for $\mathrm{MS} / \mathrm{MS}$, minimum $\mathrm{S} / N=30$ for $\mathrm{MS} / \mathrm{MS}$ precursors, MALDI spot interrogated until at least four peaks in the MSMS spectra achieved a $\mathrm{S} / N=70$. The Applied Biosystems GPS Explorer ${ }^{\mathrm{TM}_{\mathrm{V}} 3.6 \text { pro- }}$ gram was used for a combined search of MS and MS/MS data with Mascot as the search engine available at http://www.matrixscience.com/.

LC/MS/MS was performed by ABI Tempo LC MALDI using Tempo LC MALDI v.2.00.09 as a data acquisition and processing program. The ABI Protein ProteinPilot Software 2.0 Program was used for MS/MS data processing along with ABI's MS/MS search engine software Paragon.

\section{Manual confirmation of protein identification from the MS and MS/MS data (performed at Ohio University)}

MS and MS/MS data were manually submitted to MASCOT as described previously (Qiu et al. 2005; List et al. 2007a, b; Sackmann-Sala et al. 2009; Okada et al. 2010) for confirmation of the results reported by Protea Biosciences. For MS data, the searching criteria were as follows: SwissProt as the database, mouse as the species; trypsin digestion; maximum one missed cleavage; fixed carbamidome- thylation of Cys, variable modifications of oxidation$\mathrm{M}$ (methionine), pyro-Glu, monoisotopic; and $50 \mathrm{ppm}$ of peptide mass or parent tolerance. For MS/MS ion search, in addition to the above conditions, a peptide charge of +1 and a fragment mass tolerance of $0.5 \mathrm{Da}$ were used.

\section{Western blotting}

Mouse plasma proteins were subjected to 1-D and 2-D Western blotting using primary antibodies from Santa Cruz Biotechnology Inc. (Santa Cruz, CA, USA). For 1-D Western blotting, 50 ug plasma protein was diluted in $2 \%(w / v)$ SDS, $0.5 \mathrm{M}$ Tris/HCl $(\mathrm{pH} 6.8)$, $20 \%(v / v)$ glycerol, $2 \% \beta$-mecaptoethanol, and a trace of Brome phenol blue, boiled at $100^{\circ} \mathrm{C}$ for $5 \mathrm{~min}$, and loaded for SDS-PAGE. The proteins on the gel were then transferred to a PVDF membrane in a buffer containing $19.2 \mathrm{mM}$ glycine, $2.5 \mathrm{mM}$ tris and $20 \%$ $(v / v)$ methanol at $70 \mathrm{~V}$ for $2 \mathrm{~h}$ at $4^{\circ} \mathrm{C}$. Following blocking in tris-buffered saline with $1 \%$ Tween-20 (TBS/T) containing 5\% non-fat dry milk for $1 \mathrm{~h}$, the membrane was incubated with a primary antibody, [goat anti-mouse albumin ( $\mathrm{N}$ and $\mathrm{C}$ terminus specific; $1: 2,000)$, rabbit anti-mouse haptoglobin $\alpha$-chain $(1: 1,000)$ or rabbit anti-mouse transthyretin $(1: 1,000)]$, at $4{ }^{\circ} \mathrm{C}$ overnight. Following washing with TBS/T, the membrane was then incubated in horseradish peroxidase-linked secondary antibodies [either donkey anti-goat (1:5,000, Santa Cruz Biotechnology) or goat anti-rabbit (1:5,000, Millipore, Temecula, CA, USA)] for $2 \mathrm{~h}$ at room temperature. The membrane was exposed to Pierce ${ }^{\circledR}$ ECL Western blotting substrate (Thermo Scientific, Rockford, IL, USA) for $1 \mathrm{~min}$; then exposed to HyBlot CLTM autoradiography film (Denville Scientific Inc., Metuchen, NJ, USA) for 1-6 min depending on the signal strength. For 2-D Western blotting, each sample containing 750 ug of plasma protein was treated as described above for 2-DE, followed by the same immunoblotting procedure as described for 1-D Western blotting.

\section{Statistical analysis}

All statistical analyses were performed using SPSS version 14.0 software (Chicago, IL, USA). For the longitudinal experiment including data on proteomics, blood glucose, and insulin, data were subjected to 'one-way repeated measures analysis of variance 
(ANOVA)' for determination of a significant effect of aging. A significance value cutoff of $p<0.05$ was applied for glucose and insulin, whereas $p<0.01$ was used for proteomics, in order to ascertain a reliable positive screening of biomarkers of aging. For body composition, because of a cross-sectional design, oneway ANOVA was applied followed by the Fisher's least significant difference (LSD) as a post hoc test $(p<0.05)$. All data were presented as the mean \pm SEM.

\section{Results}

Body composition, insulin, and glucose levels during aging

Significant differences due to age in body weights and composition parameters including lean, fat and fluid masses $(p<0.01)$ were observed. Body weight and lean mass became significantly higher in mice aged 12 months compared to 6 months and did not change thereafter (Fig. 1a and b). Fat mass increased from 6 to 19 months, but decreased from 19 to 24 months of age (Fig. 1c). As a result, body weight increased as mice aged but decreased slightly after 19 months. Fluid mass increased at 9 and 12 months and further at 19 and 24 months of age (Fig. 1d).

Fasting glucose levels did not change with aging (Fig. 2a). Fasting plasma insulin levels significantly increased from 9 to 12 months of age $(p<0.05$, Fig. 2b). After 12 months, fasting insulin levels tended to remain relatively high, although not significantly different from those at 12 months.

\section{Identification of plasma proteins}

Approximately 150 protein spots were detected per gel and of those, 13 spots showed significant changes during aging $(p<0.01$, Table 1$)$. These spots were excised manually for MS and MS/MS identification. For three spots that did not yield high scores in MS/ MS identification, LC/MS/MS was used. The 13 spots corresponded to six proteins, four of which were identified as multiple 'isoforms' of a particular
Fig. 1 Mouse body composition at different ages. Male mice of $6(n=12), 9(n=8)$, $12(n=8), 19(n=8)$, and

24 months $(n=9)$ were used; a body weight, b lean mass, c fat mass, d fluid mass.

The data were subjected to one-way ANOVA followed by LSD as a post hoc test. Different letters denote significant differences $(p<0.05)$

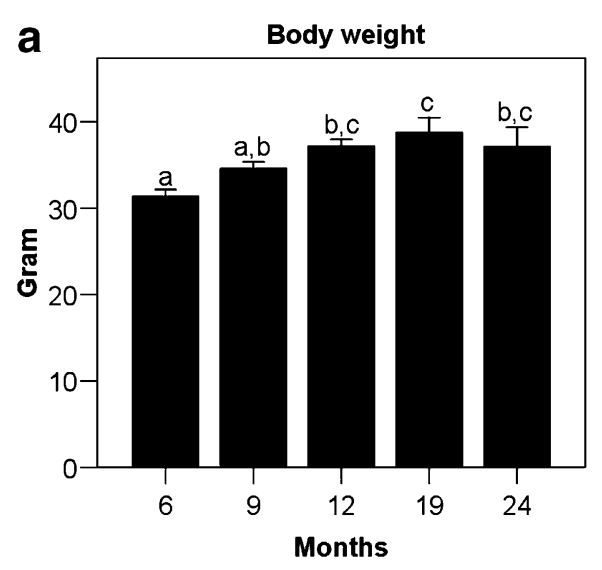

b
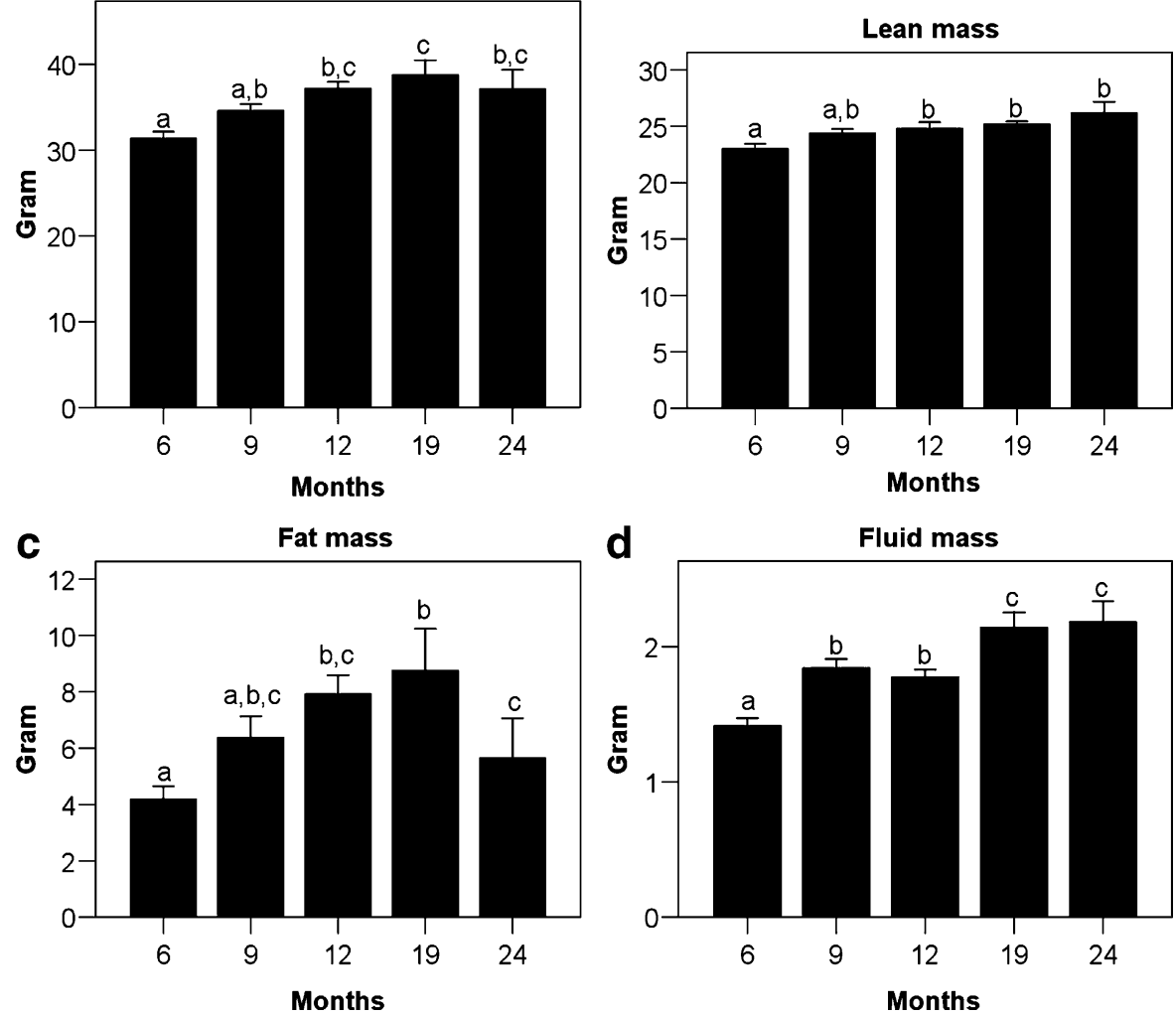


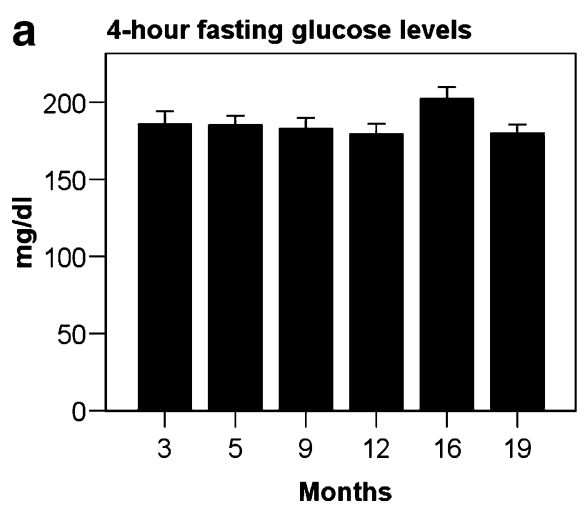

Fig. 2 Four-hour fasting plasma glucose and insulin levels; a glucose, b insulin. Repeated measures revealed no significant difference in glucose, but a significant change $(p<0.05)$ in insulin levels in the same group of mice $(n=8)$ during aging.

protein. Additional protein spots that were suspected to be isoforms of these proteins were also excised for MS/MS identification, resulting in a total of 39 spots being identified (Fig. 3). For example, 23 isoforms of albumin, seven isoforms of transthyretin (TTR), four isoforms of haptoglobin (Hp), and three isoforms of immunoglobulin kappa chain (Ig kappa) were identified. Serum amyloid protein A-1 (SAA-1), and peroxiredoxin-2 (Prx-2) were identified as single spots (Fig. 3). Detailed MS and MS/MS or LC/MS/ MS scores, as well as the Mw and $\mathrm{pI}$ of these spots are listed in the on-line resource (appended Tables a1, a2, and a3).

Plasma proteins that increased during aging

The levels of six plasma proteins were significantly increased during aging (Figs. 4, 5, 6a and d). These proteins included three isoforms of Ig kappa (Fig. 4), isoforms 2 and 3 of Hp (Fig. 5) and isoform 1 of TTR (Fig. 6a and d). The three Ig kappa isoforms did not change from 2 to 8 months but increased at 12 or 16 months of age. On the other hand, Hp isoforms 2

Table 1 Plasma proteins that change significantly $(p<0.01)$ during wild type mouse aging

\begin{tabular}{ll}
\hline Increased during aging & Decreased during aging \\
\hline Hp isoforms 2 and 3 & Prx-2 \\
Ig kappa isoforms 1-3 & Albumin isoforms 6-9 and 18 \\
TTR isoform 1 & SAA-1 \\
\hline
\end{tabular}

Isoform numbers corresponds to those labeled in Fig. 3

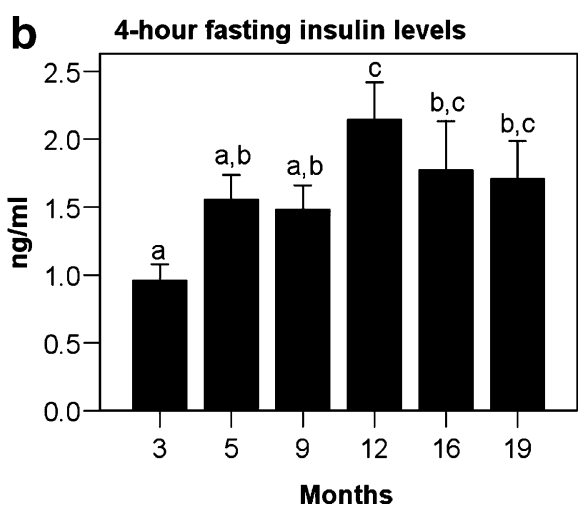

The paired sample $t$ test was used to compare insulin levels at two different ages. Different letters denote significant differences $(p<0.05)$

and 3 increased at 8 months and TTR isoform 1 increased at 4 months of age. Figure $4 d$ shows a PDQuest-generated 3-D view of the intensity of Ig kappa (isoform 1) during aging. This protein isoform was barely detectable from 2 to 8 months of age and became apparent at 16 and 19 months of age. Similarly, Ig kappa isoforms 2 and 3 became detectable only after 12 months of age (Fig. $4 \mathrm{e}$ and $\mathrm{f}$ ). Hp isoforms 2 and 3 were non-detectable at 2 and 4 months of age, increased during aging and were found to be at relatively high levels at 16 and 19 months of age (Fig. 5c). TTR isoform 1 was detectable as early as 2 months of age with a very low intensity and continued to increase to 19 months of age (Fig. 6d).

Plasma proteins that decreased during aging

Seven protein spots significantly decreased during aging $(p<0.01$, Figs. 6b, c, e and f and 7). Prx-2 was found at relatively high levels at 2 and 4 months of age but decreased after 8 months of age (Fig. $6 \mathrm{~b}$ and e). SAA-1 also decreased as mice aged (Fig. $6 \mathrm{c}$ and $\mathrm{f}$ ). Of the albumin fragments identified, five isoforms decreased during aging. These included isoforms 6-9 that decreased from 8 months of age onward (Fig. 7a-d and f) and isoform 18 that decreased after 12 months of age (Fig. 6e and g).

Western blotting confirmation of albumin, $\mathrm{Hp}$, and TTR

Selected proteins were subjected to 1-D and 2-D Western blotting analysis to confirm the MS identi- 
Fig. 3 A reference 2D gel image of proteins that significantly changed during aging. Proteins in the boxes are labeled and if more than one isoform is identified, they are numbered 1,2 , etc. Albumin isoforms are boxed in dashed lines. $M w$ molecular weight, $p I$ isoelectric point, TTR transthyretin, Ig kappa immunoglobulin kappa chain, Prx-2

peroxiredoxin-2, $S A A-1$

serum amyloid protein A-1

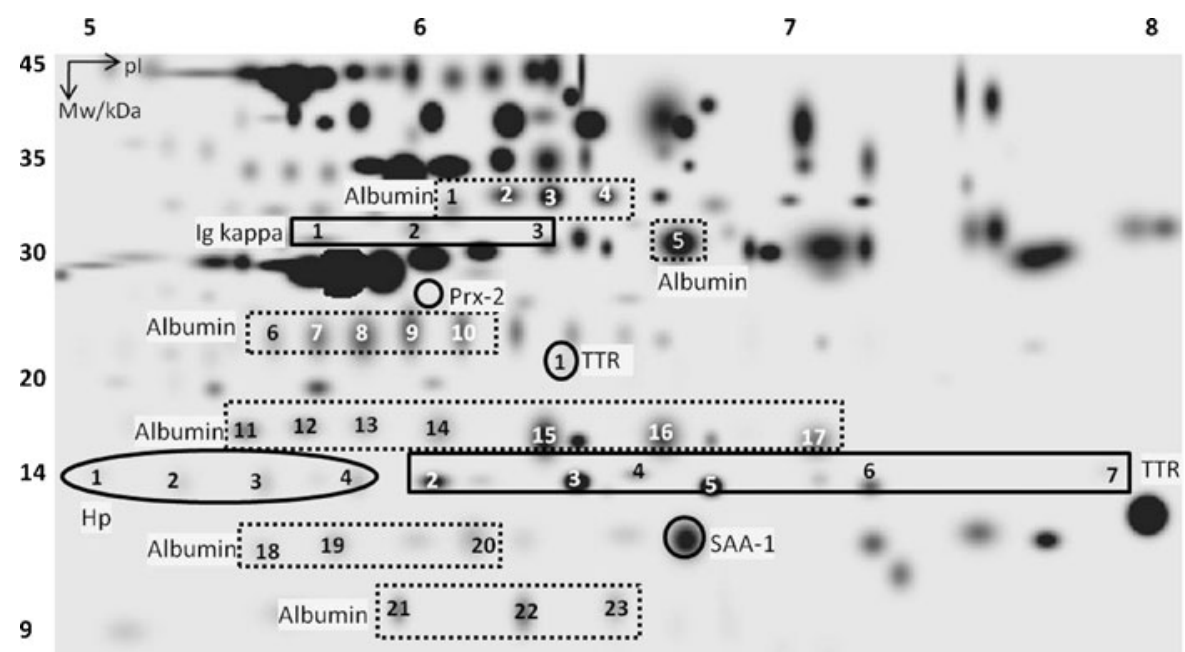

fications. As shown in Fig. 8, isoforms 1-4, 6-10, and 21-23 were confirmed as the N-terminus of albumin; isoforms 5,15 , and 16 were confirmed as C-terminus of albumin. These Western results were consistent with MS/MS identification. Out of 23 albumin isoforms, eight (isoforms 11-14, 17-20, in dashed circles) were not recognized by either the $\mathrm{N}$ or the $\mathrm{C}$ terminus albumin antibodies. Among the five

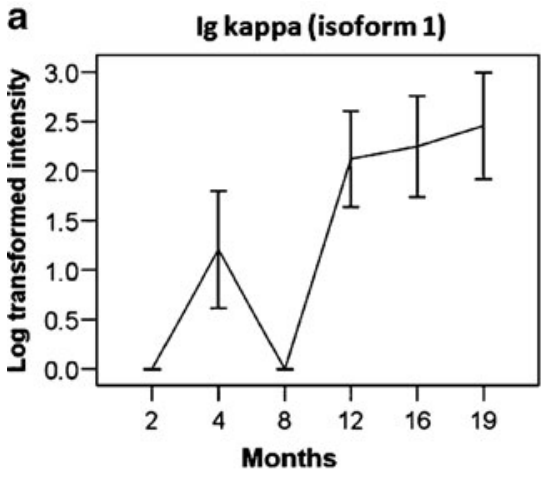

d
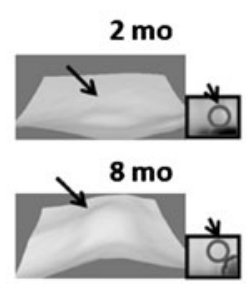

$16 \mathrm{mo}$
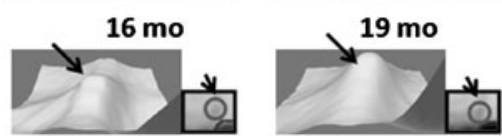

b

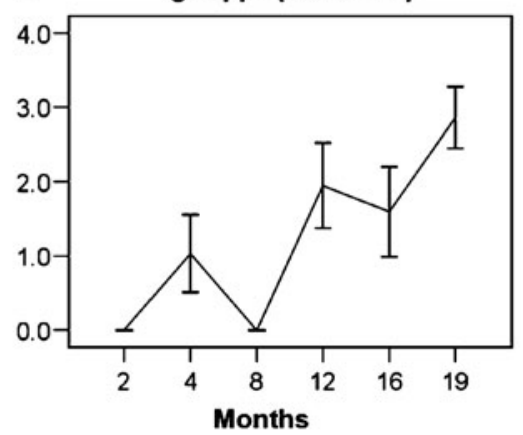

e Ig kappa (isoform 2)

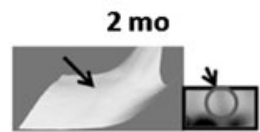

$8 \mathrm{mo}$

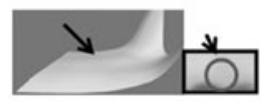

$16 \mathrm{mo}$

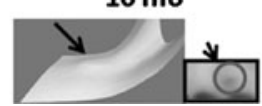

Fig. 4 Three isoforms of Ig kappa increased during mouse aging. a-c protein isoform quantification using log-transformed intensities $(y$-axis). The protein isoform number corresponds to those shown in Fig. 3. Protein intensity differences were evaluated statically using repeated measures $(p<0.01)$. d-f

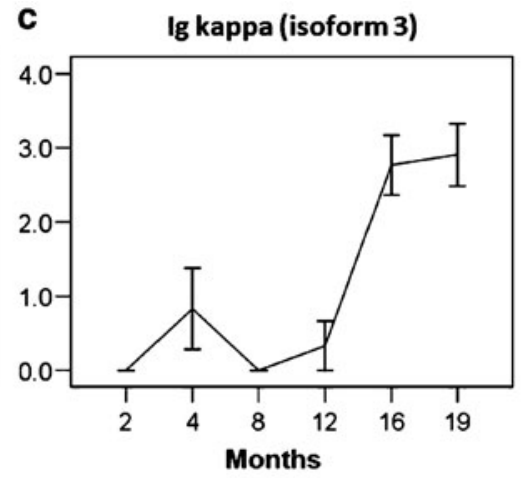

f
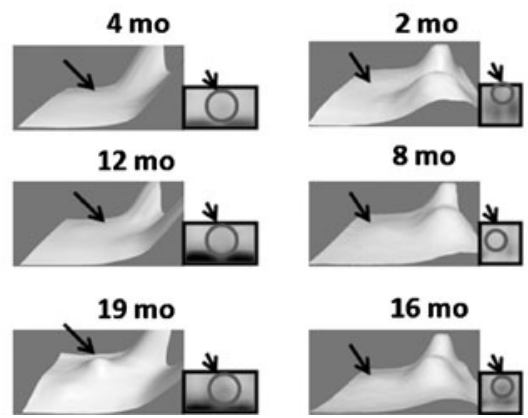

$8 \mathrm{mo}$

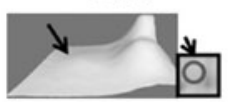

$16 \mathrm{mo}$
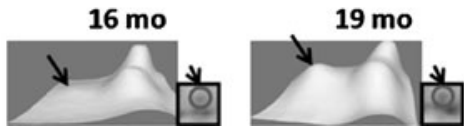

3-D view of the intensities of three Ig kappa isoforms. The spot intensities were converted into topographic views of the peaks using PDQuest. Peaks are indicated by arrows. A cropped image of an original gel is shown next to the 3-D view, with arrows indicating the corresponding protein spots 
Fig. 5 Two isoforms of $\mathrm{Hp}$ increased during mouse aging. a and b Protein isoform quantification using log-transformed intensities ( $y$-axis). The protein isoform number corresponds to those shown in Fig. 3. Protein intensity differences were evaluated statically using repeated measures $(p<0.01)$. c $3-\mathrm{D}$ view of the intensities of $\mathrm{Hp}$ isoforms 2 and 3. The spot intensities were converted into topographic views of the peaks using PDQuest. Peaks are indicated by arrows. A cropped image of an original gel is shown next to the 3 -D view with arrows indicating the corresponding protein spots
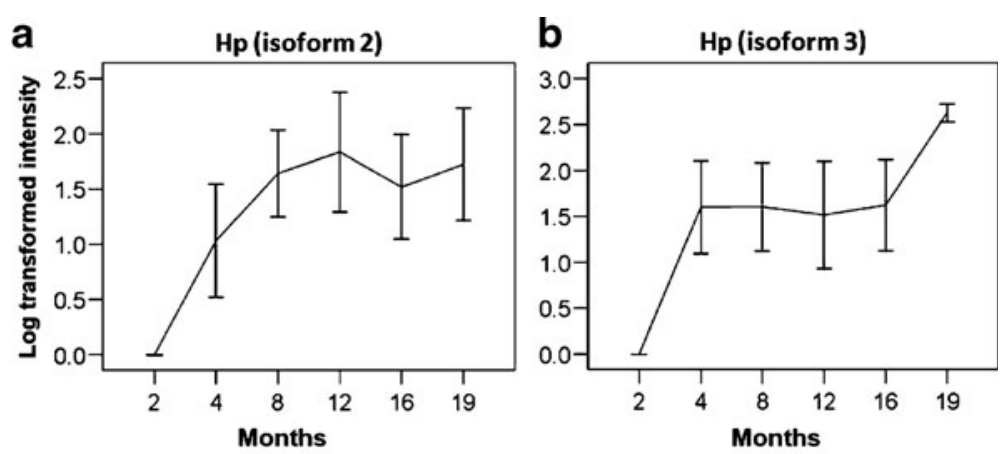

C $\quad \mathrm{Hp}$ (isoforms 2 and 3)
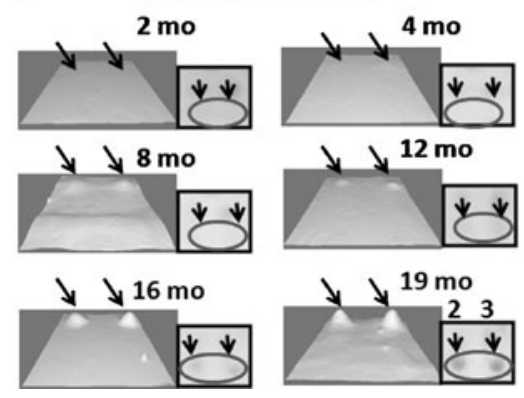

isoforms significantly changed during aging, isoforms 6-9 were confirmed by immunoblotting, but isoform 18 was not recognized by the antibody. In addition, several distinct spots that were not excised for MS analysis were recognized by albumin antibodies (spots at $30 \mathrm{kDa}$ in Fig. $8 \mathrm{a}$ and at $25 \mathrm{kDa}$ in Fig. 8c).

The four $\mathrm{Hp}$ isoforms were also confirmed by Western blotting (Fig. 9b). Two additional spots were resolved by immunoblotting at 19 months (Fig. 9b and c). Compared to the old age, only isoforms 2-4 were detectable at 2 months of age, and all four isoforms were much more prominent at 19 months of age (Fig. 9a and b). 1-D Western blotting of the plasma from four mice at 2 and 19 months of age showed dark bands at $14 \mathrm{kDa}$ in three out of four old plasma samples, but none were detectable in any of the young samples (Fig. 9d). Interestingly, 1-D Western blotting showed multiple bands between 30 and $80 \mathrm{kDa}$, perhaps due to incomplete separation of Hp from other plasma proteins such as albumin. These higher Mw bands showed no difference between 2 and 19 months.

TTR isoforms 2-7 were confirmed by Western blotting (Fig. 10a and b). There was no apparent difference in density of the spots between young and old ages examined in this study. Isoform 1 was not recognized by the antibody (indicated by dashed circle in Fig. 10c). 1-D Western blotting showed only one band at $14 \mathrm{kDa}$, and there was no difference between the levels in young and old mice (Fig. 10d).

\section{Discussion}

The results of the present study indicated several agerelated physiological and plasma proteomic changes in C57BL/6J mice. For example, lean mass reached plateau at middle age and maintained at old ages. In contrast, fat mass increased up to 19 months but decreased at 24 months. This is consistent with a recent study on longitudinal tracking of mouse body composition up to 2 years of age (Berryman et al. 2009). In humans, fat gain is associated with aging, but has been found to diminish at older ages. This wasting phenomenon in humans is also a result of muscle loss (Fanciulli et al. 2009). Although a decrease in lean mass during mouse aging was not observed, this may be a species-specific difference. Another characteristic of aging is reduced insulin sensitivity. Mice in this study maintained similar fasting glucose levels, but increased insulin levels at middle and old ages, suggesting decreased insulin sensitivity at later ages. This trend of insulin levels increasing during mouse aging has been reported previously up to 14 months of 

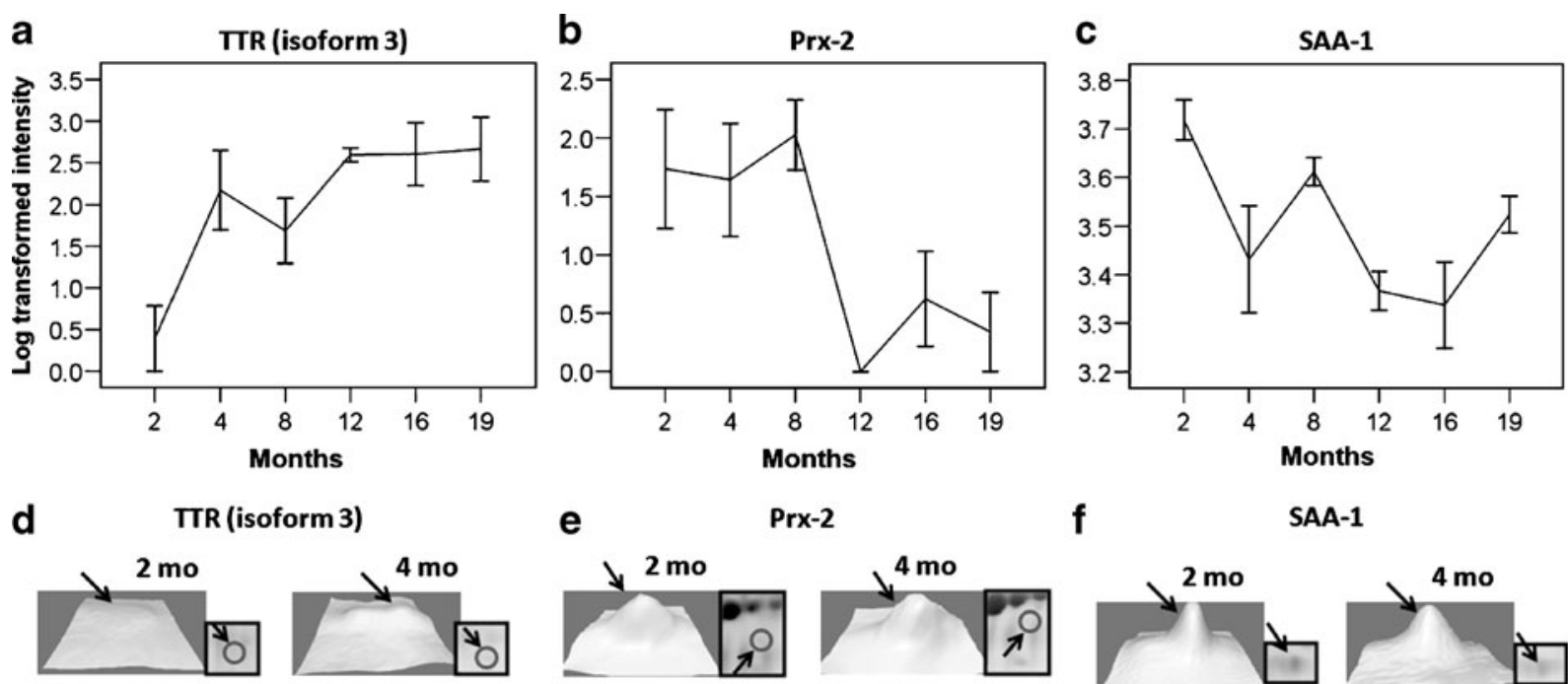

Prx-2

f

SAA-1
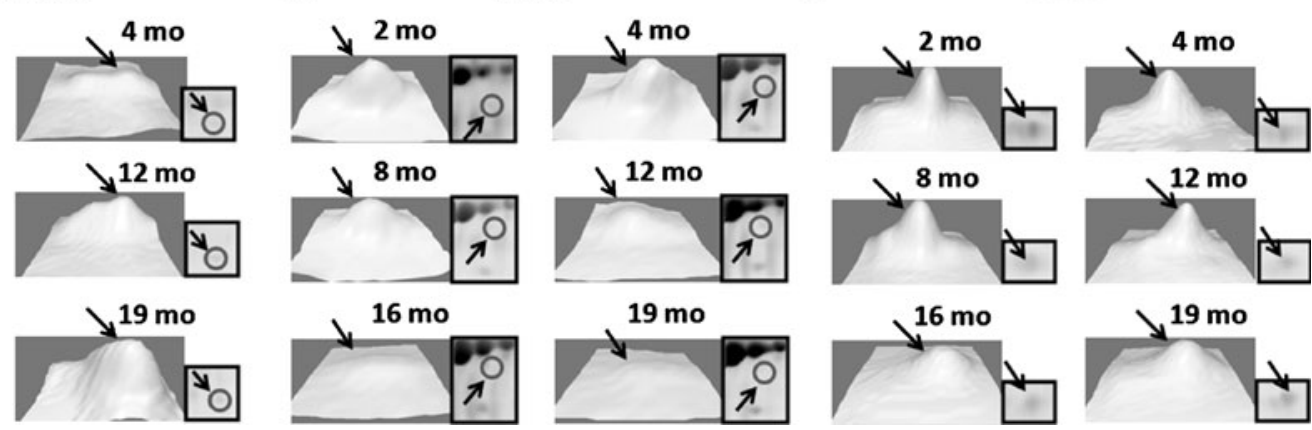

one isoform of TTR, Prx-2, and SAA-1. The spot intensities were converted into topographic views of the peaks using PDQuest. Peaks are indicated by arrows. A cropped image of an original gel is shown next to the 3-D view with arrows indicating the corresponding protein spots repeated measures $(p<0.01)$. d-f 3 -D view of the intensities of

age (Coschigano et al. 2003). The onset of increased insulin levels coincided with fat mass gain, suggesting an association of increased fat mass with insulin resistance (Muhlhausler and Smith 2009).

The proteomic approach resolved several plasma proteins that changed during the natural course of mouse aging. One problem in quantifying plasma proteins is that a few species of abundant proteins occupy most of the protein mass (Anderson and Anderson 2002). Albumin, for example, comprises of $60 \%$ of total serum protein mass (Rothemund et al. 2003). These highly abundant proteins often result in high background 'smearing' of proteins on 2D gels (Thadikkaran et al. 2005). Immuno-based albumin depletion kits often result in depletion of other proteins (Granger et al. 2005). Using a commercially available mouse albumin removal kits, we observed an 'over-depletion' of many plasma proteins, with markedly decreased protein intensities below $30 \mathrm{kDa}$ on the 2-D gel (data now shown). More importantly, in the initial series of experiments, we found the intensities of several albumin fragments to change as a function of age. Therefore, we chose not to deplete albumin, but used relatively high concentration of polyacrylamide gels $(15 \%)$ to resolve proteins with masses below $\sim 45 \mathrm{kDa}$ which is smaller than albumin $(\sim 66 \mathrm{kDa})$.

We have identified 13 protein spots that significantly changed during normal aging. These spots corresponded to six proteins. Spots that were identified as the same protein were termed 'isoforms', which, in most cases, differ in pI but maintain the same Mw, suggesting post-translational modifications (PTMs) that alter the charge of the proteins. There are more than 800 known PTMs (UNIMOD database available at http://www. unimod.org/modifications_list.php). For detailed discussion on possible PTMs for these proteins, see the on-line source 'Appended Discussion' section. While 

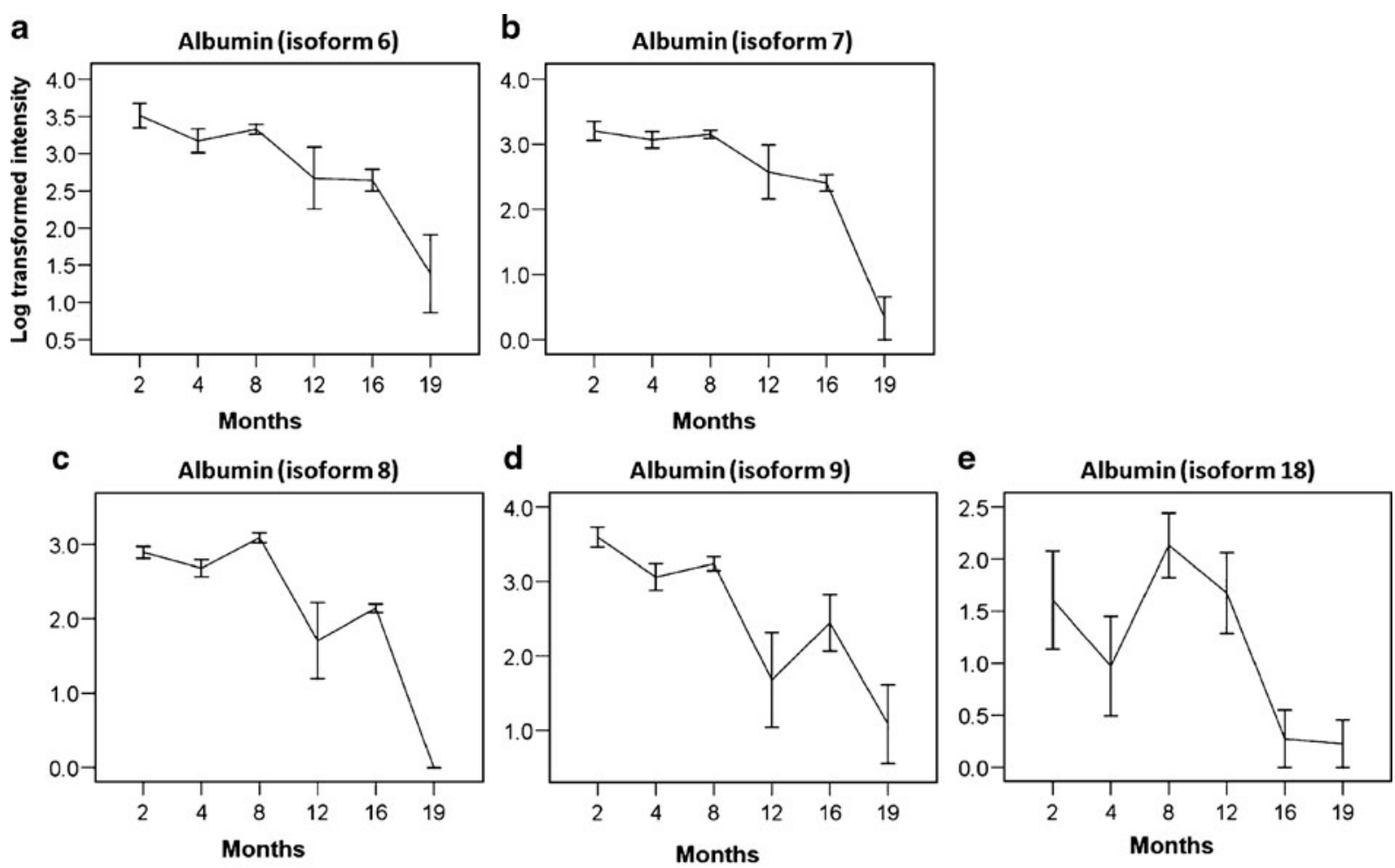

f
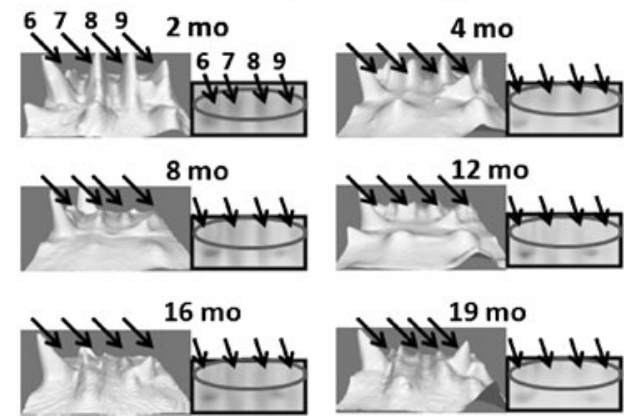

Fig. 7 Five isoforms of albumin fragments decreased during mouse aging. a-e Protein isoform quantification using logtransformed intensities ( $y$-axis). The albumin isoform number corresponds to those shown in Fig. 3. Isoform intensity differences were evaluated statically using repeated measures $(p<0.01)$. f 3 -D view of the intensities of albumin isoforms

most of the isoforms reported here are consistent with literature in terms of $\mathrm{Mw}$ and $\mathrm{pI}$ on the 2-D gel, one novel finding was that as many as 23 albumin isoforms were identified as opposed to $<10$ isoforms reported previously (Duan et al. 2004; Gazzana and Borlak 2008; Roberto et al. 2008; Bijon and Jürgen 2009). Further, 15 of these isoforms were also confirmed by immunoblotting. g Albumin (isoform 18)

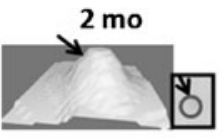

$8 \mathrm{mo}$

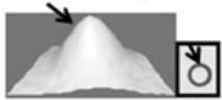

$16 \mathrm{mo}$

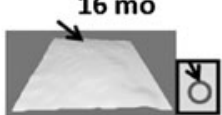

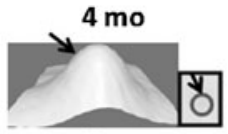

$12 \mathrm{mo}$

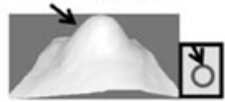

$19 \mathrm{mo}$

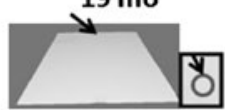

6-9. g 3-D view of the intensity of albumin isoform 18 . The spot intensities were converted into topographic views of the peaks using PDQuest. Peaks are indicated by arrows. A cropped image of an original gel is shown next to the 3-D view, with arrows indicating the corresponding protein spots

The advantage of 2-D gel versus 2-D Western blotting is that on a 2-D gel, the entire proteome can be examined, whereas only proteins recognized by a certain antibody are detected by 2-D Western analysis. 1-D Western blotting generates data on the 'total' level of proteins recognized by an antibody to a specific epitope on a given protein. Also, conventional treatment of proteins for 1-D SDS-PAGE does not 
Fig. 8 2-D Western blotting of albumin isoforms. a 2-D Western result using antibody against the $\mathrm{N}$ terminus of albumin. b 2-D gel image showing isoforms identified as $\mathrm{N}$ terminal fragments of albumin by MS/MS. c 2-D Western result using antibody against the $\mathrm{C}$ terminus of albumin. d 2-D gel image showing isoforms identified as $\mathrm{C}$ terminal fragments of albumin by MS/MS. Albumin isoforms that were not recognized by Western blotting are circled in dashed lines in $\mathbf{b}$ and $\mathbf{d}$

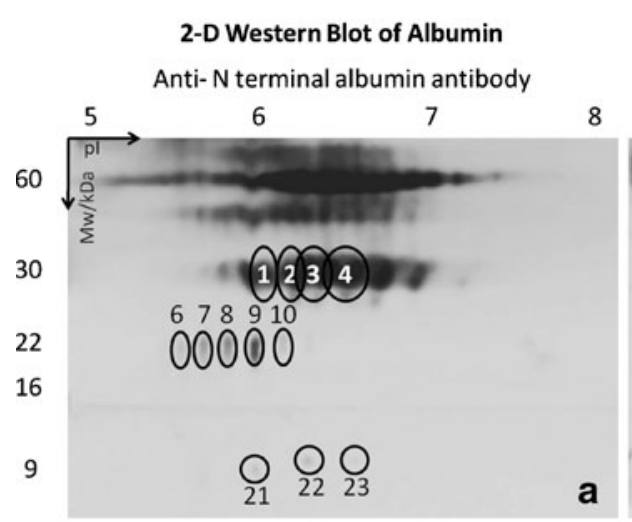

2-D Gel Image Showing Albumin Isoforms 1-23

6
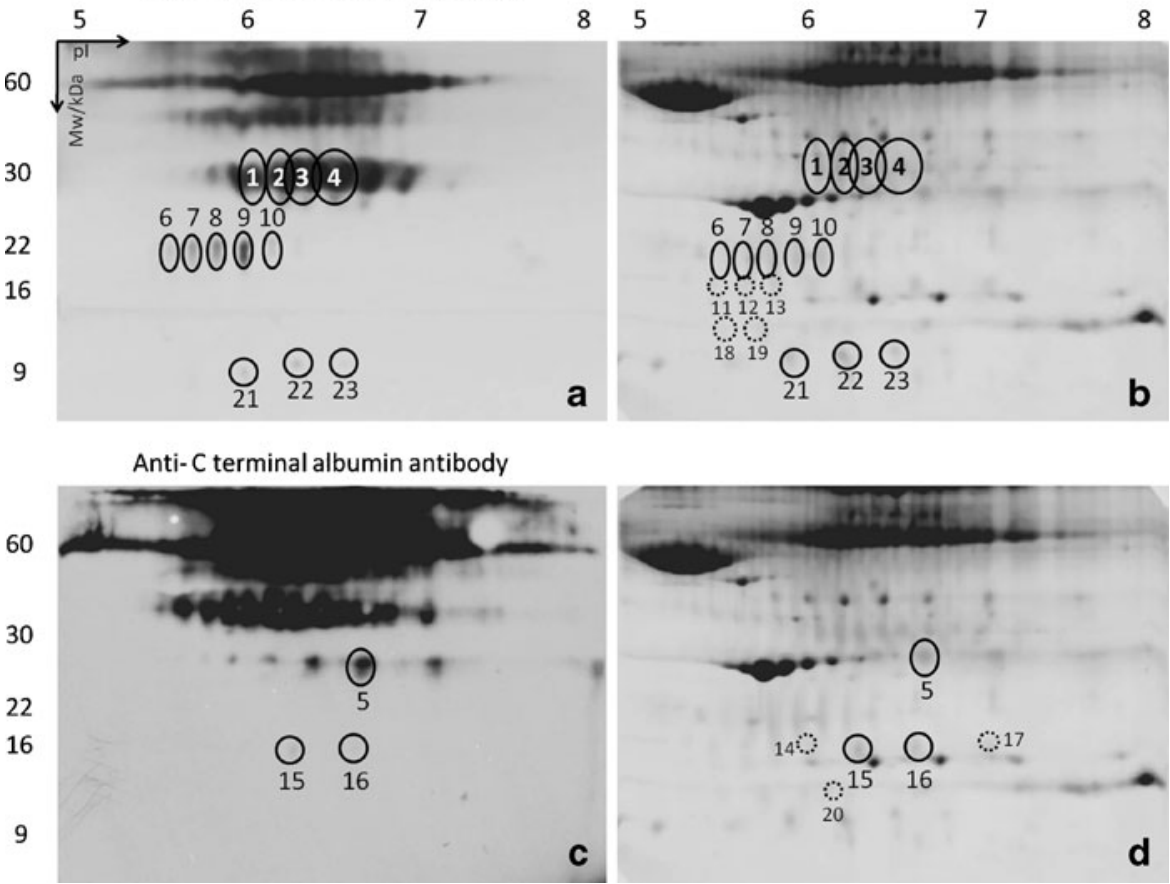

seem to separate proteins sufficiently, as shown by heavy bands at higher Mw region in Fig. 9d compared to only light streaking in Fig. 9a and b. Regarding identification of proteins by 2 -DE/MS/MS versus Western blotting, we have found that each method yielded similar results in terms of albumin fragments, Hp and TTR. Because the albumin isoforms described in this study were either $\mathrm{N}$ or $\mathrm{C}$ terminal fragments based on MS/MS data (on-line source Table a1), two antibodies specific to $\mathrm{N}$ and $\mathrm{C}$ termini of mouse albumin were used. Overall the 2-D Western blotting resulted in a similar pattern of albumin isoforms compared to 2-DE with $\mathrm{MS} / \mathrm{MS}$ identification. Hp was identified as the alpha subunit for four spots and all these have been confirmed by 2-D Western blotting using an antibody specific for $\mathrm{Hp}$ alpha subunit. The 2-D pattern of TTR was also very similar on the Western blotting film compared to 2-D gels. However, albumin and TTR antibodies failed to recognize certain protein isoforms that were detected by 2-D gel electrophoresis. This may be due to PTMs changing the epitopes of a given protein which inhibits recognition by the antibody. This is a limitation of immuno-based method versus identification by $\mathrm{MS}$ and $\mathrm{MS} / \mathrm{MS}$.

\section{TTR}

The majority of plasma TTR is derived from the liver and transports and increases half-life of thyroxine and retinol binding protein-4 (RBP-4) in blood. Plasma TTR and RBP-4 both increase in type II diabetic subjects (Raila et al. 2007). RPB-4 is implicated in insulin resistance (Kowalska et al. 2008), although this has become controversial (Chen et al. 2009). Interestingly, RBP-4 levels positively correlate with age (Chen et al. 2009). In humans, TTR levels also increase as a function of age (Robert et al. 1999). Thus, it appears that RBP-4 and its carrier protein TTR both increase as humans age.

A condition called senile systemic amyloidosis caused by TTR amyloid deposits has been found to affect people older than 80 years (Westermark et al. 1990) and is the primary cause of death for people over 110 years of age (Leslie 2008). TTR is a protein that can form plaques that deposit systemically in its wild-type form (Westermark et al. 1990). Interestingly, of the 80 different human TTR mutants found, many are more susceptible to amyloid formation (Plant Ã-Bordeneuve and Said 2000). One specific PTM, a thiol conjugation, is found to be dependent on 


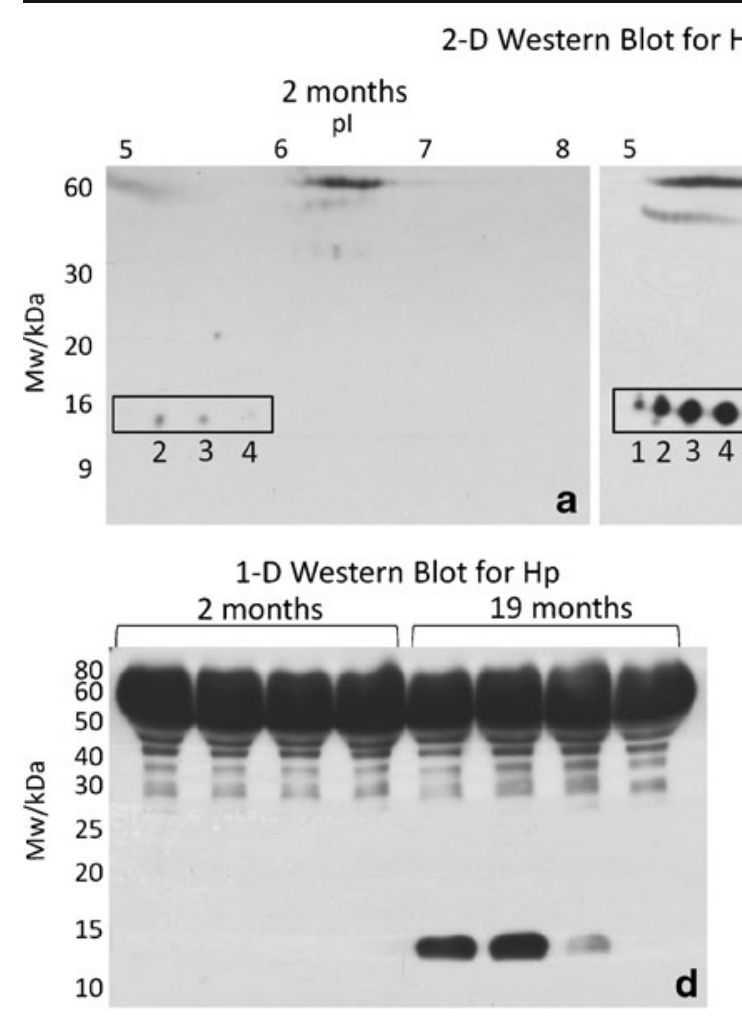

Fig. 9 Confirmation of $\mathrm{Hp}$ isoforms by Western blotting. a 2-D Western result from 2-month-old mouse. b 2-D Western result from the same mouse at 19 months of age. c 2-D gel image

the age of a person and its increase is indicative of symptomatic amyloid disease (Suhr et al. 1999). Thus, PTMs of TTR may be related to amyloid formation and/or toxicity. Importantly, one TTR isofom increased during mouse aging and its PTM may be of interest for further investigation.

\section{Hp}

Hp isoforms 2 and 3 increased during mouse aging, although Hp could not be detected by 2-DE at 2 months of age (young), consistent with a previous study which does not detect $\mathrm{Hp}$ in normal male (6 weeks old) mouse plasma until inflammation is induced by burn injury or infection (Duan et al. 2004). During hemolysis in blood vessels, Hp binds to hemoglobin to protect against heme-induced oxidative stress. Hp is also an acute phase protein and is highly induced in the liver by inflammation and injury (Dobryszycka 1997). In elder people, high concentration of $\mathrm{Hp}$ is correlated with infection or inflammation (Katz et al. 1990). Also, it
2-D Gel Image Showing

Hp Isoforms 1-4

19 months

pl

8

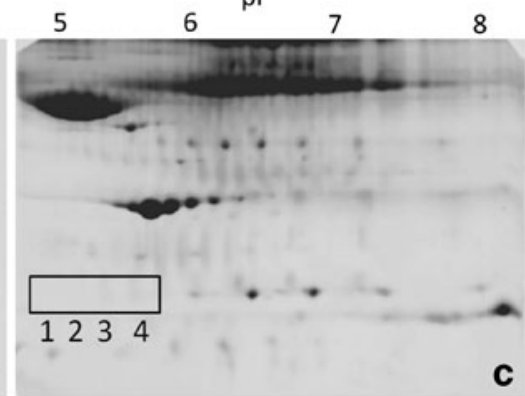

showing isoforms identified as Hp by MS/MS and LC/MS/MS. d 1-D Western blotting of plasma proteins from four mice at 2 months of age and the same mice at 19 months of age

has been found that in healthy aging populations, serum concentrations of $\mathrm{Hp}$ are negatively correlated with cognitive performance (Teunissen et al. 2003). In one proteomic study using 2-DE, Hp is found preferably in old but rarely in young aorta tissues, potentially indicating senescent vessels (Song et al. 1985). In diabetes, acute phase proteins including $\mathrm{Hp}$ increase in the serum (McMillan 1989). Hp has been known to be a major susceptibility gene in diabetic vascular complications in humans (Asleh and Levy 2005). Different alleles of $\mathrm{Hp}$ in humans are thought to have different antioxidant efficiencies, resulting in different susceptibilities to diabetic nephropathy, retinopathy, and cardiovascular disease (Bessa et al. 2007; Nakhoul et al. 2007). Increased inflammation is associated with aging (Ferrucci et al. 2005). As increased inflammation appears to be a common theme for both diabetes and aging (Dowling and Simmons 2009), it is possible that Hp plays a role in both processes. Thus, the increased Hp isoforms in this study may indicate a state of increased inflammation at older ages. 


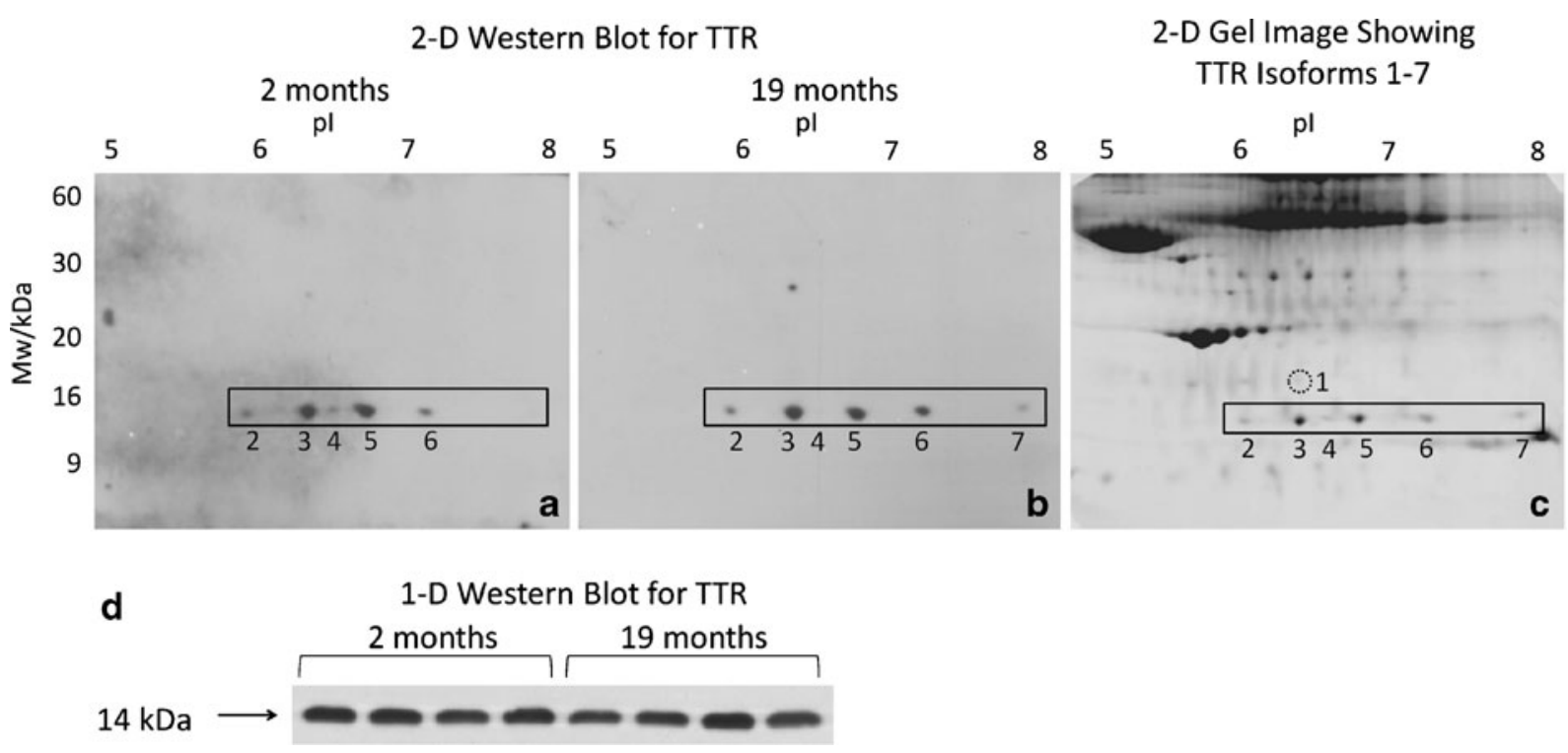

Fig. 10 Confirmation of TTR isoforms by Western blotting. a 2-D Western result from 2-month-old mouse. b 2-D Western result from the same mouse at 19 months of age. c 2-D gel image showing isoforms identified as TTR by MS/MS and

Ig kappa

The present study found three Ig kappa isoforms to be increased during mouse aging. The significance of this is not clear. Interestingly, older people tend to have higher serum concentrations of immunoglobulins A and G (Gonzalez-Quintela et al. 2008). It is possible that increased immunoglobulins indicate an increased inflammatory state at old age. However, in contrast to a general increase in immunoglobulins, specific antibodies raised against pathogens such as Streptococcus pneumoniae are actually decreased in older people compared to the younger generation (Simell et al. 2008), indicating a weakened immune system at old age. Also, the immune system has been shown to be affected by aging in mice (Richard et al. 2005). For example, $\mathrm{T}$ cells from old mice show defects in activation upon antigen stimulation, partially caused by hyperglycosylation of T-cell surface glycoproteins (Richard et al. 2005). Therefore, Ig kappa isoform changes reported in this study may be of interest for future aging study of the immune system.

\section{$\operatorname{Prx}-2$}

Prx-2 is an anti-oxidant enzyme involved in reducing peroxide levels in cells. Prx-2 resides in
LC/MS/MS. Isoform 1 (circled in dashed line) was not recognized in Western blotting shown in a and b. d 1-D Western blotting of plasma proteins from four mice at 2 months of age and the same mice at 19 months of age

cytoplasm and is not a typical secreted protein, thus it may be derived from ruptured cells. However, it has been detected in mouse serum by 2-DE (Guipaud et al. 2007) with a similar Mw and $\mathrm{pI}$ as reported here. Interestingly, serum Prx-2 levels have been found to decrease after mice have been exposed to skin irradiation (Guipaud et al. 2007). In Caenorhabditis elegans, Prx protects against oxidative stress and heat stress, as well as promotes longevity (OlÃhovÃ et al. 2008). In rats, PrX-2 is induced in primary astrocyte cultures from young rats (1 month) but not adult or aged rats (9 and 24 months of age) after exposure to X-ray irradiation (Miura et al. 2007). In terms of intracellular signaling, Prx-2 inhibits mouse embryonic fibroblast senescence by inhibiting the Ras-ERKNF $\kappa$ B pathway (Han et al. 2006). Together, the evidence suggests that Prx-2 protects against oxidative stress and may inhibit oxidative damage during aging. Our finding that Prx- 2 decreased as mice aged perhaps indicated reduced capacity to process reactive oxygen species at older ages. Oxidative stress is associated with aging and suggested by some to be the major factor responsible for the aging process (Dowling and Simmons 2009). Our result with Prx-2 supports oxidative stress as part of the mechanism of aging. 


\section{Albumin}

In humans, a lower serum albumin concentration is found in the elderly (Robert et al. 1999; Gom et al. 2007; Nakamura and Miyao 2007). In terms of agerelated diseases, higher serum albumin levels are found to be associated with reduced cardiovascular mortality, coronary heart disease, and stroke incidence (Gillum 2000). In rats, serum albumin concentration increases from 3 to 7 months of age, then decreases at 12 and 20 months of age (Barber et al. 1995). Interestingly, the five mouse albumin fragments observed in the present study showed little change from 2 to 8 months of age, but decreased from 8 to 19 months of age. However, the reduced levels of these albumin fragments were not necessarily due to the reduction of total albumin concentration because several of the other albumin fragments actually increased during aging (not reported because $p$ values were not below cut-off value of 0.01 ). In addition, only albumin fragments smaller than $45 \mathrm{kDa}$ were resolved as individual spots on the gels. It is possible that while total albumin in blood decreased at old age, certain fragments increased whereas others decreased or remained the same.

\section{SAA-1}

SAA-1 is found to be associated with high-density lipoprotein (HDL). It is known that lipid profiles change during aging (Kronmal et al. 1993; Bittner 2003). For example, non-HDL cholesterol increases in the elderly (Bittner 2003) and HDL decreases during aging (Wilson et al. 1994). Total cholesterol is positively correlated with increased mortality at age 40 , but this correlation becomes increasingly less obvious at ages 50,60, and 70. At age 80, total cholesterol is negatively correlated with mortality, that is, lower serum cholesterol levels are associated with an increase in death rate (Kronmal et al. 1993). HDL is associated with decreased cardiovascular disease risks and increased cognitive function (Atzmon et al. 2002) and is found at higher levels in centenarians (Nir et al. 2001). In humans, SAA-1 is also the precursor of reactive amyloid fibrils in type AA amyloidosis, a condition caused by deposition of insoluble fibrillar amyloid proteins (a degraded $\mathrm{N}$-terminus fragment of SAA) in the extracellular space in many organs and tissues (Merlini and Bellotti 2003). Several alleles have been discovered with different susceptibilities to amyloid formation, e.g., SAA1.1 is more susceptible than SAA1.5 (van der Hilst et al. 2008).

In conclusion, this longitudinal study of the mouse plasma proteome revealed several proteins to be significantly changed during aging. These proteins and/or isoforms thereof are biomarkers of mouse aging. The proteins described in this report are involved in many aspects of aging or age-related diseases. Prx-2 and Hp are antioxidant proteins that protect against oxidative stress which is an important aspect of aging. Reduced Prx-2 may indicate reduced antioxidative capacity, whereas increased $\mathrm{Hp}$ may imply an increased demand to cope with heme-related damage/stress at old age. This is also consistent with the nature of $\mathrm{Hp}$ as an acute phase protein that is up regulated during injury or inflammation, which is associated with old age. SAA-1 and TTR have primary roles in transportation and metabolism, but are also involved in amyloid formation in blood vessels or tissues, a phenomenon associated with old age. The increase of the specific TTR isoform at old age found in this study may be involved in amyloid formation. In addition, albumin is involved in cardiovascular health while TTR has been associated with insulin resistance. Increases in TTR and decreases in albumin may contribute to morbidity and mortality at old age.

Future studies using transgenic or knockout mouse models of these proteins may unravel the functions of these proteins in aging. Of particular interest is that different isoforms of the same protein did not always show the same profile relative to each other or with the total protein levels during aging (e.g., albumin and TTR). These plasma proteins may be posttranslationally modified in the cell or after they are released into circulation. Unraveling the chemical nature of the PTMs, their tissue of origin, and their regulation during the aging process will hopefully shed light on the molecular mechanisms of aging. Extension of these results to humans is of obvious importance. Finally, as biomarkers of aging become available, they could be used to monitor successful anti-aging intervention strategies, including therapeutics, which hopefully will result in increased lifespan and, perhaps more importantly, improved healthspan of an individual. 
Acknowledgment This work was supported by World AntiDoping Agency (WADA), Diabetes Research Initiative and by the State of Ohio's Eminent Scholars Program that includes a gift by Milton and Lawrence Goll. JJK also is supported by the following grants: National Institute of Health (NIH) R15DK075436, NIH R01AG019899, and 1P01AG031736-01A1.

We thank Dr. Edward List for reading and commenting on this manuscript.

\section{References}

Anderson NL, Anderson NG (2002) The human plasma proteome: history, character, and diagnostic prospects. Mol Cell Proteomics 1:845-867

Asleh R, Levy AP (2005) In vivo and in vitro studies establishing haptoglobin as a major susceptibility gene for diabetic vascular disease. Vasc Health Risk Manag 1:19-28

Atzmon G, Gabriely I, Greiner W, Davidson D, Schechter C, Barzilai N (2002) Plasma HDL levels highly correlate with cognitive function in exceptional longevity. J Gerontol A Biol Sci Med Sci 57:M712-M715

Ballesteros M, Fredriksson A, Henriksson J, Nystrom T (2001) Bacterial senescence: protein oxidation in non-proliferating cells is dictated by the accuracy of the ribosomes. EMBO J 20:5280-5289

Barber BJ, Babbitt RA, Parameswaran S, Dutta S (1995) Agerelated changes in rat interstitial matrix hydration and serum proteins. J Gerontol A Biol Sci Med Sci 50A: B282-B287

Berryman DE et al (2009) Two-year body composition analyses of long-lived GHR null mice. J Gerontol A Biol Sci Med Sci:glp175

Bessa SS, Hamdy SM, Ali EMM (2007) Haptoglobin gene polymorphism in type 2 diabetic patients with and without nephropathy: an Egyptian study. Eur J Intern Med 18:489495

Bijon C, Jürgen B (2009) A 2-DE MALDI-TOF study to identify disease regulated serum proteins in lung cancer of c-myc transgenic mice. Proteomics 9:1044-1056

Bittner V (2003) Non-high-density lipoprotein cholesterol and cardiovascular disease. Curr Opin Lipidol 14:367-371

Bradford MM (1976) A rapid and sensitive method for the quantitation of microgram quantities of protein utilizing the principle of protein-dye binding. Anal Biochem 72:248-254

Chen CC et al (2009) Levels of retinol-binding protein 4 and uric acid in patients with type 2 diabetes mellitus. Metabolism 58(12):1812-1816

Colman RJ et al (2009) Caloric restriction delays disease onset and mortality in rhesus monkeys. Science 325:201-204

Coschigano KT, Holland AN, Riders ME, List EO, Flyvbjerg A, Kopchick JJ (2003) Deletion, but not antagonism, of the mouse growth hormone receptor results in severely decreased body weights, insulin, and insulin-like growth factor I levels and increased life span. Endocrinology 144:3799-3810. doi:10.1210/en.2003-0374

Dobryszycka W (1997) Biological functions of haptoglobinnew pieces to an old puzzle. Eur J Clin Chem Clin Biochem 35:647-654
Dowling DK, Simmons LW (2009) Reactive oxygen species as universal constraints in life-history evolution. Proc Biol Sci 276:1737-1745

Duan X, Yarmush DM, Berthiaume F, Jayaraman A, Yarmush ML (2004) A mouse serum two-dimensional gel map: application to profiling burn injury and infection. Electrophoresis 25:3055-3065

Fanciulli G, Delitala A, Delitala G (2009) Growth hormone, menopause and ageing: no definite evidence for 'rejuvenation' with growth hormone. Hum Reprod Update 15:341-358

Ferrucci L et al (2005) The origins of age-related proinflammatory state. Blood 105:2294-2299

Gazzana G, Jr B (2008) Mapping of the serum proteome of hepatocellular carcinoma induced by targeted overexpression of epidermal growth factor to liver cells of transgenic mice. J Proteome Res 7:928-937

Gillum RF (2000) Assessment of serum albumin concentration as a risk factor for stroke and coronary disease in African Americans and whites. J Natl Med Assoc 92:3-9

Gom I et al (2007) Relationship between serum albumin level and aging in community-dwelling self-supported elderly population. J Nutr Sci Vitaminol (Tokyo) 53:37-42

Gonzalez-Quintela A et al (2008) Serum levels of immunoglobulins (IgG, IgA, IgM) in a general adult population and their relationship with alcohol consumption, smoking and common metabolic abnormalities. Clin Exp Immunol 151:42-50

Granger J, Siddiqui J, Copeland S, Remick D (2005) Albumin depletion of human plasma also removes low abundance proteins including the cytokines. Proteomics 5:4713-4718

Gromov P, Skovgaard GL, Palsdottir H, Gromova I, Ostergaard M, Celis JE (2003) Protein profiling of the human epidermis from the elderly reveals up-regulation of a signature of interferon-\{gamma\}-induced polypeptides that includes manganese-superoxide dismutase and the p85\{beta\} subunit of phosphatidylinositol 3-kinase. Mol Cell Proteomics 2:70-84

Guipaud O et al (2007) Time-course analysis of mouse serum proteome changes following exposure of the skin to ionizing radiation. Proteomics 7:3992-4002

Han Y-H, Kwon J-H, Yu D-Y, Moon E-Y (2006) Inhibitory effect of peroxiredoxin ii (prx ii) on Ras-Erk-NFkb pathway in mouse embryonic fibroblast (MEF) senescence. Free Radic Res 40:1182-1189

Harper JM, Wolf N, Galecki AT, Pinkosky SL, Miller RA (2003) Hormone levels and cataract scores as sex-specific, mid-life predictors of longevity in genetically heterogeneous mice. Mech Ageing Dev 124:801-810

Holloszy JO, Fontana L (2007) Caloric restriction in humans. Exp Gerontol 42:709-712

Ingram DK (2000) Age-related decline in physical activity: generalization to nonhumans. Med Sci Sports Exerc 32:1623-1629

James MH, Adam BS, Scott FL, Andrzej TG, Richard AM (2007) Skin-derived fibroblasts from long-lived species are resistant to some, but not all, lethal stresses and to the mitochondrial inhibitor rotenone. Aging Cell 6:1-13

Katz PR, Karuza J, Gutman SI, Bartholomew W, Richman G (1990) A comparison between erythrocyte sedimentation rate (esr) and selected acute-phase proteins in the elderly. Am J Clin Pathol 94:637-640 
Klein BEK, Klein R, Lee KE (2002) Incidence of age-related cataract over a 10-year interval: the beaver dam eye study. Ophthalmology 109:2052-2057

Kowalska I et al (2008) Serum retinol binding protein 4 is related to insulin resistance and nonoxidative glucose metabolism in lean and obese women with normal glucose tolerance. J Clin Endocrinol Metab 93:2786-2789

Kronmal RA, Cain KC, Ye Z, Omenn GS (1993) Total serum cholesterol levels and mortality risk as a function of age. A report based on the Framingham data. Arch Intern Med 153:1065-1073

Leslie M (2008) Aging: searching for the secrets of the super old. Science 321:1764-1765

List EO et al (2007a) Application of bioinformatics and scalable computing to perform proteomic analysis of stomach tissue from diabetic mice. Scalable Comput Pract Exp 8:173-183

List EO et al (2007b) Analysis of mouse skin reveals proteins that are altered in a diet-induced diabetic state: a new method for detection of type 2 diabetes. Proteomics 7:1140-1149

List EO, Palmer AJ, Berryman DE, Bower B, Kelder B, Kopchick JJ (2009) Growth hormone improves body composition, fasting blood glucose, glucose tolerance and liver triacylglycerol in a mouse model of dietinduced obesity and type 2 diabetes. Diabetologia 52 (8): $1647-1655$

Mair W, Dillin A (2008) Aging and survival: the genetics of life span extension by dietary restriction. Annu Rev Biochem 77:727-754

Malone JP, Radabaugh MR, Leimgruber RM, Gerstenecker GS (2001) Practical aspects of fluorescent staining for proteomic applications. Electrophoresis 22:919-932

McMillan DE (1989) Increased levels of acute-phase serum proteins in diabetes. Metabolism 38:1042-1046

Merlini G, Bellotti V (2003) Molecular mechanisms of amyloidosis. N Engl J Med 349:583-596

Miller RA (1996) The aging immune system: primer and prospectus. Science 273:70-74

Miller RA, Nadon NL (2000) Principles of animal use for gerontological research. J Gerontol A Biol Sci Med Sci 55:B117-B123

Miura Y et al (2007) Proteomic study on x-irradiationresponsive proteins and ageing: search for responsible proteins for radiation adaptive response. J Biochem 142:145-155

Muhlhausler B, Smith SR (2009) Early life origins of metabolic dysfunction: role of the adipocyte. Trends Endocrinol Metab 20:51-57

Nakamura E, Miyao K (2007) A method for identifying biomarkers of aging and constructing an index of biological age in humans. J Gerontol A Biol Sci Med Sci 62:1096-1105

Nakhoul FM, Miller-Lotan R, Awaad H, Asleh R, Levy AP (2007) Hypothesis - haptoglobin genotype and diabetic nephropathy. Nat Clin Pract Nephrol 3:339-344

Nass R, Johannsson G, Christiansen JS, Kopchick JJ, Thorner MO (2009) The aging population-is there a role for endocrine interventions? Growth Horm IGF Res 19:89100
Nir B, Ilan G, Magda G, Nancy I, John DS (2001) Offspring of centenarians have a favorable lipid profile. J Am Geriatr Soc 49:76-79

Okada S, List E, Sankaran S, Kopchick J (2010) Plasma protein biomarkers correlated with the development of dietinduced type 2 diabetes in mice. Clinical Proteomics 6 (1-2):6-17. doi:10.1007/s12014-009-9040-5

OlÃhovÃ M et al (2008) A redox-sensitive peroxiredoxin that is important for longevity has tissue- and stress-specific roles in stress resistance. Proc Natl Acad Sci USA 105:19839-19844

Orentreich N, Brind JL, Vogelman JH, Andres R, Baldwin H (1992) Long-term longitudinal measurements of plasma dehydroepiandrosterone sulfate in normal men. J Clin Endocrinol Metab 75:1002-1004

Palmer AJ et al (2009) Age-related changes in body composition of bovine growth hormone transgenic mice. Endocrinology 150:1353-1360

Plant $\tilde{A}$-Bordeneuve V, Said G (2000) Transthyretin related familial amyloid polyneuropathy. Curr Opin Neurol 13:569-573

Qiu L, List EO, Kopchick JJ (2005) Differentially expressed proteins in the pancreas of diet-induced diabetic mice. Mol Cell Proteomics 4:1311-1318

Raila J, Henze A, Spranger J, Mohlig M, Pfeiffer AF, Schweigert FJ (2007) Microalbuminuria is a major determinant of elevated plasma retinol-binding protein 4 in type 2 diabetic patients. Kidney Int 72:505-511

Richard AM et al (2005) T cells in aging mice: genetic, developmental, and biochemical analyses. Immunol Rev 205:94-103

Robert FR, Glenn EP, Louis MN, Olga N (1999) Reference distributions for the negative acute-phase proteins, albumin, transferrin, and transthyretin: a comparison of a large cohort to the world's literature. J Clin Lab Anal 13:280286

Roberto G et al (2008) Proteomic analysis of the pathophysiological process involved in the antisnake venom effect of mucuna pruriens extract. Proteomics 8:402-412

Rothemund DL, Locke VL, Liew A, Thomas TM, Wasinger V, Rylatt DB (2003) Depletion of the highly abundant protein albumin from human plasma using the gradiflow. Proteomics 3:279-287

Sackmann-Sala L, Ding J, Frohman LA, Kopchick JJ (2009) Activation of the GH/IGF-1 axis by cjc-1295, a longacting ghrh analog, results in serum protein profile changes in normal adult subjects. Growth Horm IGF Res 19:471-477

Sato $\mathrm{Y}$ et al (2006) Identification and characterization of an increased glycoprotein in aging: age-associated translocation of cathepsin d. Mech Ageing Dev 127:771-778

Simell B, Lahdenkari M, Reunanen A, Kayhty H, Vakevainen $M$ (2008) Effects of ageing and gender on naturally acquired antibodies to pneumococcal capsular polysaccharides and virulence-associated proteins. Clin Vaccine Immunol 15:1391-1397

Song J, Stastny J, Fosslien E, Robertson AL Jr (1985) Effect of aging on human aortic protein composition. II. Twodimensional polyacrylamide gel electrophoretic analysis. Exp Mol Pathol 43:297-304 
Suhr OB et al (1999) Impact of age and amyloidosis on thiol conjugation of transthyretin in hereditary transthyretin amyloidosis. Amyloid 6:187-191

Teunissen CE et al (2003) Inflammation markers in relation to cognition in a healthy aging population. J Neuroimmunol 134:142-150

Thadikkaran L, Siegenthaler MA, Crettaz D, Queloz PA, Schneider P, Tissot JD (2005) Recent advances in bloodrelated proteomics. Proteomics 5:3019-3014

van der Hilst JCH, Yamada T, Op den Camp HJM, van der Meer JWM, Drenth JPH, Simon A (2008) Increased susceptibility of serum amyloid a 1.1 to degradation by mmp-1: potential explanation for higher risk of type aa amyloidosis. Rheumatology (Oxford) 47:1651-1654

Westermark P, Sletten K, Johansson B, Cornwell GG 3rd (1990) Fibril in senile systemic amyloidosis is derived from normal transthyretin. Proc Natl Acad Sci USA 87:2843-2845

Wilson PW, Anderson KM, Harris T, Kannel WB, Castelli WP (1994) Determinants of change in total cholesterol and HDL-c with age: the Framingham study. J Gerontol 49: M252-M257

Yuan RPB (2008) Aging study: lifespan and survival curves. In: http://phenome.jax.org/phenome/protodocs/yuan2/ cut_200804/yuan2.xls 